\title{
Rancang Bangun Alat Ukur Kelajuan dan Arah Angin Menggunakan Sistem Telemetri Nirkabel dengan Transceiver nRF24L01+
}

\author{
Okky Frananda Putra*, Rahmat Rasyid, Harmadi \\ Jurusan Fisika FMIPA Universitas Andalas \\ Kampus Unand, Limau Manis, Padang, 25163 \\ *ofranandaputra@yahoo.com
}

\begin{abstract}
ABSTRAK
Telah dirancang bangun sebuah alat ukur kelajuan dan arah angin menggunakan sistem telemetri nirkabel. Sistem terdiri dari dua unit yaitu transmitter dan receiver. Unit transmitter berfungsi sebagai pengukur nilai kelajuan dan arah angin menggunakan sensor optocoupler ITR9608-F yang terdapat pada modul FC-03. Data nilai kelajuan dan arah angin ditransmisikan oleh transceiver nRF24L01+ yang memanfaatkan gelombang elektromagnet pada frekuensi gelombang radio 2,4 GHz. Data akan diterima oleh transceiver nRF24L01+ di unit receiver lalu ditampilkan pada LCD (Liquid Crystal Display). Hasil penelitian menunjukkan bahwa sistem telemetri nirkabel mampu mentransmisikan data dengan jangkauan maksimum $1000 \mathrm{~m}$ dengan kondisi tanpa penghalang, $650 \mathrm{~m}$ dengan kodisi ada penghalang saat cuaca cerah, dan $485 \mathrm{~m}$ dengan kondisi ada penghalang saat cuaca hujan $485 \mathrm{~m}$. Persentase kesalahan rata-rata alat ukur kelajuan angin ini dihitung dan dibandingkan dengan beberapa alat acuan, 4,54 \% dengan anemometer Lutron AM-4206 dan 7,65 \% dengan anemometer mangkuk milik BMKG Stasiun Meteorologi Kelas II BIM Padang Pariaman. Alat ukur arah angin menampilkan delapan arah mata angin dengan sudut sebesar $45^{\circ}$. Alat ukur arah angin berhasil mendeteksi dan menampilkan arah angin yang sama dengan anemometer mangkuk milik BMKG.

Kata kunci: telemetri nirkabel, transceiver nRF24L01+, kelajuan angin, arah angin
\end{abstract}

\section{ABSTRACT}

Wind speed and direction measuring instrument has been designed using a wireless telemetry system. The system consists of two units, transmitter and receiver. The function of transmitter unit is to measure the wind speed and wind direction using the ITR9608-F optocoupler sensor in the FC-03 module. Wind speed and wind direction data are transmitted by nRF24LO1+ transceiver utilizing electromagnetic waves at $2.4 \mathrm{GHz}$ radio frequency. The data will be received by the nRF24L01+ transceiver in the receiver unit and then displayed on the LCD (Liquid Crystal Display). The results showed that wireless telemetry systems were able to transmit data with maximum range of $1000 \mathrm{~m}$ without barrier, $650 \mathrm{~m}$ with barrier in fine weather, and $485 \mathrm{~m}$ with barrier in rainy weather. The average percentage error of this wind speed measuring instrument was calculated and compared with some reference instruments, $4.54 \%$ compared with anemometer Lutron AM-4206 and 7.65\% compared with anemometer bowl which belongs to BMKG meteorological station class II BIM Padang Pariaman. This wind direction instrument displayed eight wind direction with an angle of $45^{\circ}$. The wind direction measuring instrument successfully detected and displayed the same wind direction as anemometer bowl which belongs to BMKG.

Keywords: wireless telemetry, transceiver $n R F 24 L 01+$, wind speed, wind direction

\section{PENDAHULUAN}

Potensi angin di suatu tempat dapat diketahui berdasarkan kelajuan dan arah anginnya. Alat yang digunakan untuk mengukur kelajuan dan arah angin adalah anemometer (Middleton,1969). Anemometer mangkuk telah digunakan di BMKG Stasiun Meteorologi Kelas II BIM Padang Pariaman terdiri dari sistem tiga mangkuk. Nilai kelajuan dan arah angin dikirim ke penampil yang berada di ruang kendali dengan penghubung kabel. Sistem penghubung kabel yang panjang rentan mengalami masalah pada kerusakan secara fisik dan mengharuskan pengecekan pada kabel.

Pesma (2013) telah merancang alat ukur kelajuan dan arah angin menggunakan sensor fotodioda. Sensor dioda membutuhkan komponen tambahan seperti LED sebagai sumber cahayanya. Alat ini tidak menggunakan sistem penghubung kabel, sehingga alat ini memiliki kekurangan yang mengharuskan melihat langsung ke alat ukur untuk pengambilan data.

Hudaya (2013) telah memanfaatkan modul KYL 1020-U sebagai sistem telemetri nirkabel untuk monitoring kelajuan dan arah angin. Modul ini dapat mengirimkan data kelajuan dan arah angin bersamaan. Jarak pengiriman data maksimum $100 \mathrm{~m}$ dengan penghalang 
dinding. Derek (2016) telah menggunakan sistem telemetri untuk pengiriman data kelajuan angin dengan memanfaatkan modul transceiver nRF24L01 dan menggunakan sensor optocoupler sebagai sensornya. Sensor optocoupler sangat praktis karena terdapat LED infra merah dan fototranssistor, sehingga tidak memerlukan komponen lain. Modul ini dapat mengirim data pada jarak maksimum $80 \mathrm{~m}$ dengan penghalang dinding. Modul transceiver nRF24L01 telah dikembangkan menjadi transceiver nRF24L01+. Modul ini dapat mengirim data sejauh $1 \mathrm{~km}$ dengan ditambahkan sebuah antena eksternal.

Berdasarkan masalah di atas maka dilakukan penelitian rancang bangun alat ukur kelajuan dan arah angin menggunakan sistem telemetri nirkabel sebagai media pengiriman data. Sistem telemetri nirkabel yang digunakan adalah transceiver nRF24L01+ dengan tambahan antena eksternal. Sensor yang digunakan adalah optocoupler ITR9608-F sebagai sensor kelajuan dan arah angin. Sistem telemetri nirkabel ini diharapkan dapat memudahkan pemantauan nilai kelajuan dan arah angin dari jarak yang jauh.

\section{METODE}

\subsection{Alat dan Bahan}

Alat dan bahan yang digunakan dalam perancangan ini terdiri dari optocoupler ITR9608-F yang terdapat pada modul FC-03 yang digunakan sebagai sensor kelajuan dan arah angin, arduino uno R3 digunakan untuk memproses data, transceiver nRF24L01+ digunakan sebagai pengirim dan penerima data jarak jauh, LCD (Liquid Crystal Display) digunakan sebagai penampil data.

\subsection{Perancangan Diagram Blok Sistem}

Perancangan perangkat keras ini diawali dengan penginderaan besaran fisis (kelajuan dan arah angin) oleh modul FC-03. Pada alat ukur kelajuan angin terdapat satu modul sensor, sedangkan pada alat ukur arah angin terdapat delapan modul sensor dimana satu sensor mewakili satu arah angin. Keluaran modul sensor ini berupa tegangan digital yang diproses oleh arduino uno R3 dan data tersebut akan dikirim oleh transceiver nRF24L01+ di unit transmitter. Data akan diterima transceiver nRF24L01+ di unit receiver lalu akan diproses lagi oleh arduino uno R3. Data tersebut akan ditampilkan di LCD backpack. Diagram blok sistem dapat dilihat pada Gambar 1. Alat ukur kelajuan dan arah angin ini diproses dengan menggunakan arduino uno R3 yang berbeda. Satu buah transceiver nRF24L01+ dihubungkan dengan satu arduino uno R3, karena transceiver nRF24L01+ hanya mengirim dan menerima satu buah besaran.

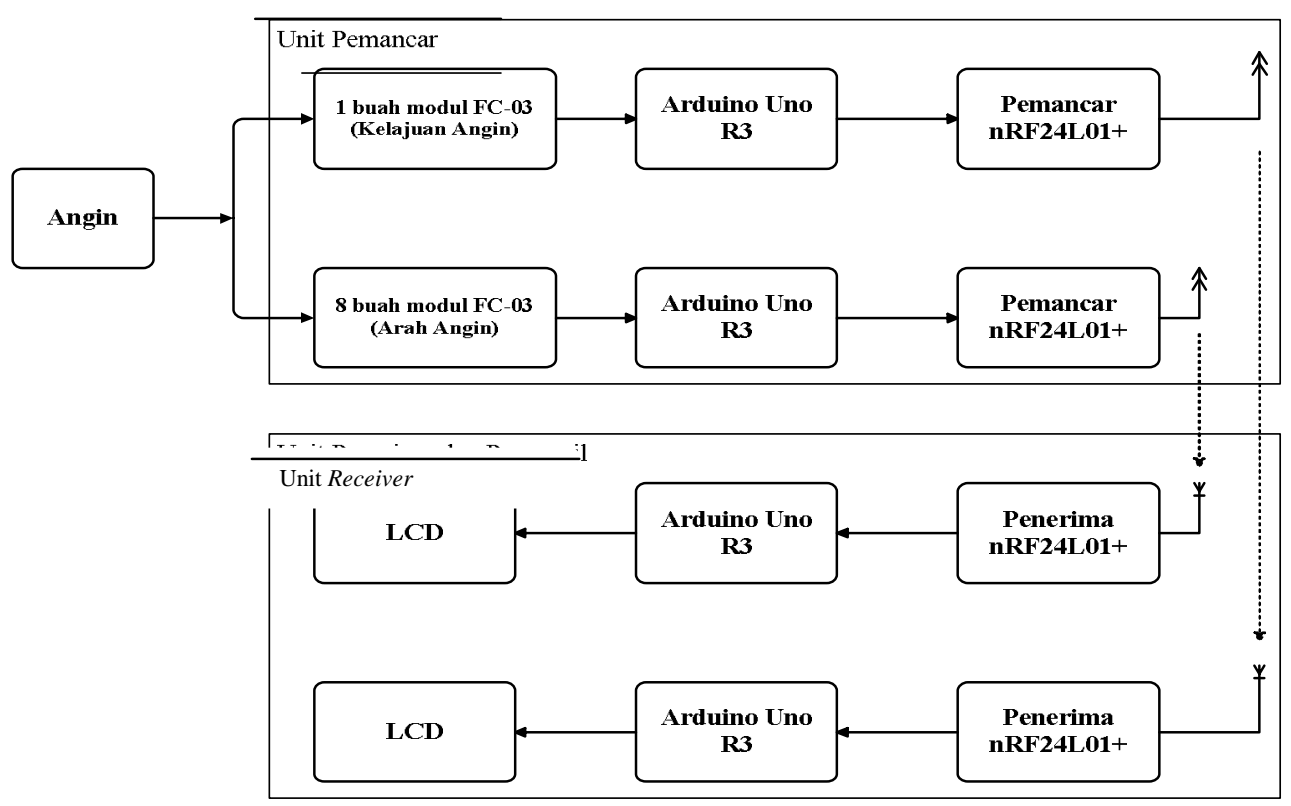

Gambar 1 Diagram blok sistem alat ukur kelajuan dan arah angin 


\subsection{Perancangan Sensor Kelajuan Angin}

Sensor kelajuan angin menggunakan satu buah optocoupler ITR9608-F (modul FC-03) yang dihubungkan dengan arduino uno R3. Rangkaian ini berfungsi untuk mengetahui kelajuan angin. Skema rangkaian dapat dilihat pada Gambar 2. Sensor optocoupler ITR9608-F pada modul FC-03 akan mendeteksi banyaknya putaran per detik dengan mengkonversinya menjadi pulsa-pulsa sinyal. Pulsa-pulsa sinyal akan diproses oleh arduino uno R3 untuk mendapatkan nilai rpm (rotasi per menit). Data yang telah diolah akan dikirimkan ke unit receiver melalui transceiver nRF24L01+ dan akan diolah kembali oleh arduino uno R3 untuk mendapatkan nilai kelajuan angin yang akan di tampilkan pada LCD.

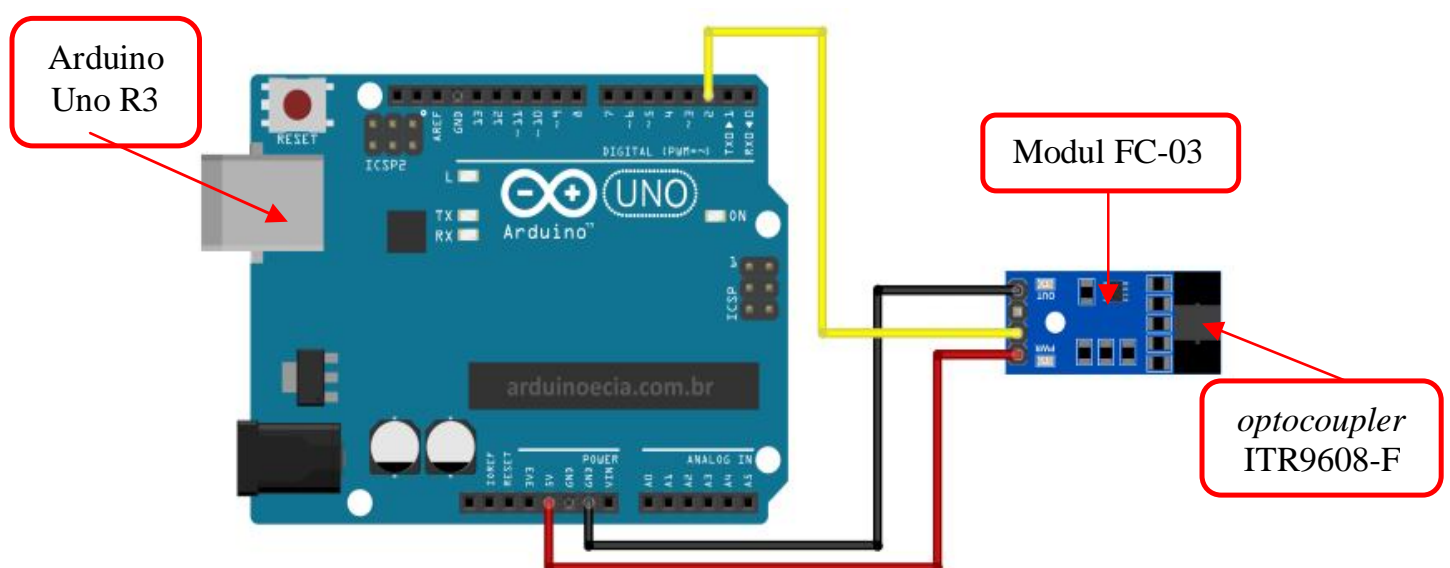

Gambar 2 Skema rangkaian sensor kelajuan angin

\subsection{Perancangan Sensor Arah Angin}

Sensor arah angin menggunakan delapan buah optocoupler ITR9608-F (modul FC-03) yang dihubungkan ke arduino uno R3. Satu modul sensor mewakili satu arah mata angin. Perancangan ini berfungsi untuk mengetahui arah angin. Skema rangkaian sensor arah angin dapat dilihat pada Gambar 3. Sensor optocoupler ITR9608-F pada modul FC-03 akan mendeteksi ada atau tidaknya penghalang pada sensor yang akan mengeluarkan sinyal digital high atau low. Sinyal digital akan diproses oleh arduino uno R3 untuk mendapatkan nilai arah angin. Data yang telah diolah akan dikirimkan ke unit receiver melalui transceiver nRF24L01+ dan akan ditampilkan pada LCD.

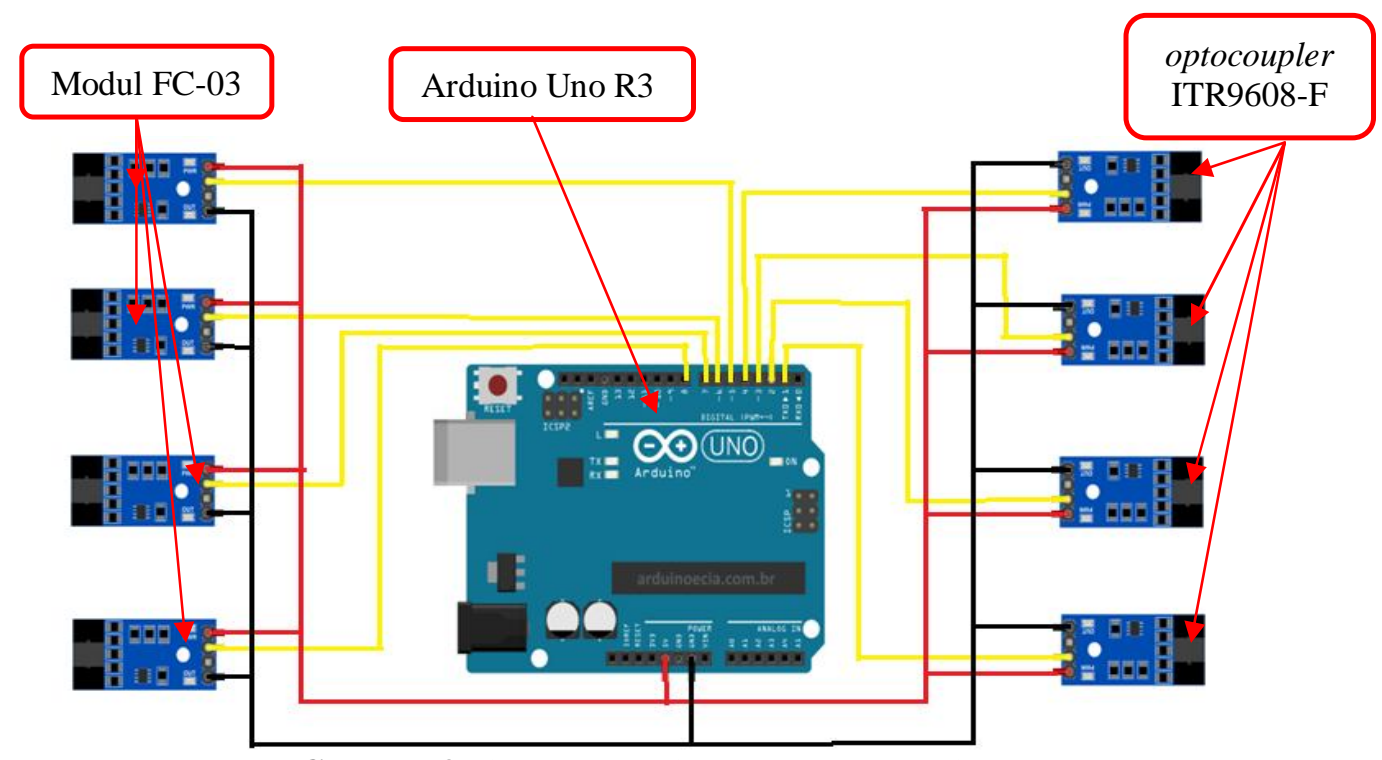

Gambar 3 Skema rangkaian sensor arah angin 


\section{HASIL DAN DISKUSI}

\subsection{Karakterisasi Transceiver nRF24L01+}

Karakterisasi transceiver nRF24L01+ dilakukan untuk mengetahui jangkauan terjauh pengiriman data dari transmitter ke receiver. Data yang akan dikirim yaitu berupa kode desimal 26. Rangkaian transceiver dengan arduino uno R3 dari setiap unit dihubungkan dengan adaptor dan upload program karakterisasi melalui software arduino 1.6.6 pada komputer. Karakterisasi ini dilakukan di daerah Banda Kali Simpang Haru dan Universitas Andalas, Padang, Sumatra Barat dengan pengukuran jarak maksimum pengiriman data menggunakan google map.

Tabel 1 Hasil pengujian karakterisasi transceiver nRF24L01+

\begin{tabular}{cccc}
\hline \multirow{2}{*}{ Kondisi Lapangan } & \multicolumn{2}{c}{ Kode Pengiriman Data } & \multirow{2}{*}{ Jarak Maksimum } \\
\cline { 2 - 3 } & Unit Pemancar & Unit Penerima & Pengiriman Data (m) \\
\hline Tanpa Penghalang & 26 & 26 & 1000 \\
Ada Penghalang, Cuaca Cerah & 26 & 26 & 650 \\
Ada Penghalang, Cuaca Hujan & 26 & 26 & 485 \\
\hline
\end{tabular}

Jangkauan maksimum pengiriman data transceiver nRF24L01+ pada saat tidak ada penghalang menyentuh sampai $1000 \mathrm{~m}$. Jangkauan pengiriman data transceiver nRF24L01+ berkurang ketika kondisi topografi terdapat banyak penghalang seperti pohon, tembok, kontur tanah, dan cuaca. Berdasarkan Tabel 1 jarak pengiriman data maksimum pada kondisi ada penghalang dan cuaca cerah didapatkan $650 \mathrm{~m}$, sedangkan ketika ada penghalang dan cuaca hujan didapatkan $485 \mathrm{~m}$. Jarak pengiriman data berkurang dikarenakan gelombang radio yang dipancarkan oleh transceiver nRF24L01+ mengalami absorption (penyerapan), refleksi (pemantulan) dan scattering (hamburan) ketika terhalang.

\subsection{Pengujian Rancang Alat Secara Keseluruhan}

\subsubsection{Pengujian Rancang Alat Secara Keseluruhan Skala Laboratorium}

Pengujian alat ukur secara keseluruhan skala laboratorium ini dilakukan di Laboratorium Elektronika dan Instrumentasi Jurusan Fisika Universitas Andalas. Pada pengujian ini untuk melihat ketepatan data yang didapatkan oleh alat ukur kelajuan dan arah angin yang di bandingkan dengan anemometer lutron AM-4206. Pengambilan data dilakukan secara bersamaan dimana alat ukur diletakan bersebelahan dengan anemometer lutron AM4206. Sumber angin berasal dari kipas angin miyako KAD-1227B dengan dua jenis variasi yaitu variasi jarak dan variasi sudut. Variasi jarak digunakan untuk melihat ketepatan pengukuran kelajuan angin. Variasi sudut dilakukan untuk melihat respon alat ukur kelajuan dan arah angin dalam menunjukkan arah angin tanpa membandingkan dengan anemometer lutron AM-4206 di karenakan alat tersebut tidak dapat mengetahui arah anginnya.

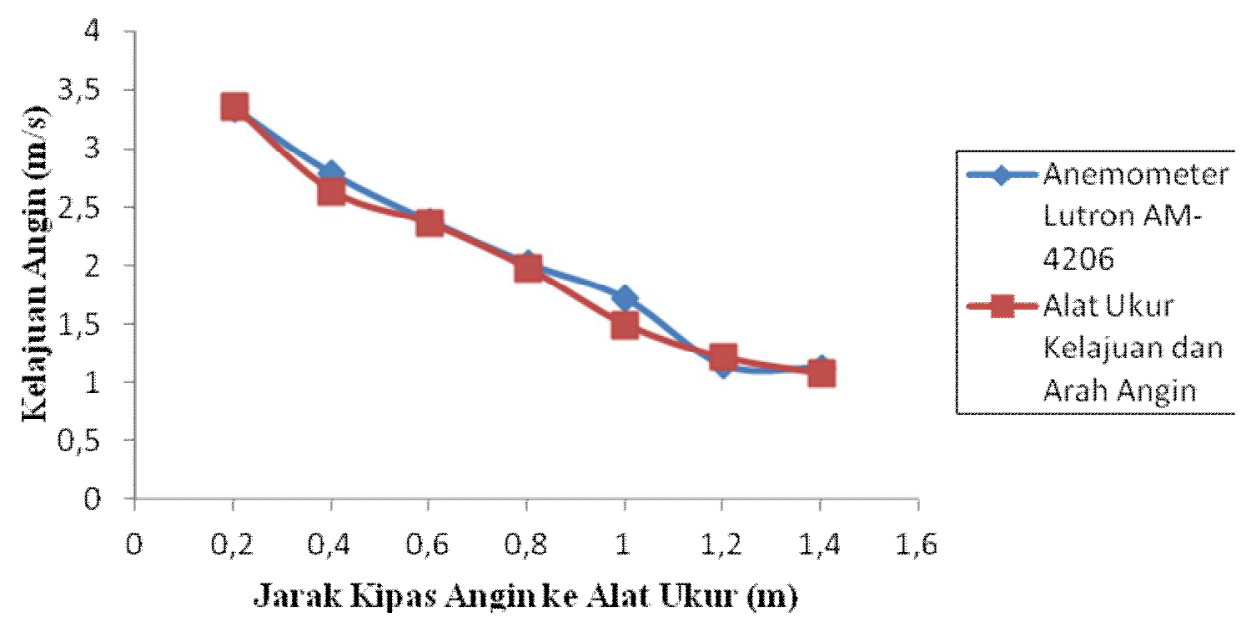

Gambar 4 Grafik hasil pengujian rancang alat secara keseluruhan skala laboratorium terhadap variasi jarak 
Variasi jarak kipas angin ke alat ukur digunakan dari 0,2 m-1,4 m. Pada Gambar 4 menunjukkan semakin jauh jarak kipas angin ke alat maka semakin kecil nilai kelajuan angin yang terbaca pada alat. Jarak kipas angin yang semakin jauh dari alat akan menyebabkan angin dari kipas menyebar keruangan, sehingga nilai kelajuan angin akan semakin kecil.

Persentase kesalahan rata-rata yang didapatkan setelah membandingkan kedua alat ini adalah 4,54 \%. Nilai kelajuan yang terukur pada alat ukur kelajuan dan arah angin sedikit terdapat perbedaan dengan anemometer lutron AM-4206.

Perbedaan terdapat pada bentuk baling-baling alat. Bentuk baling-baling pada alat ukur kelajuan dan arah angin menggunakan sistem tiga mangkuk, sedangkan anemometer lutron AM-4206 memiliki bentuk baling-baling yang terdiri dari bilah-bilah. Alat ukur kelajuan dan arah angin dapat menerima hembusan angin dari arah manapun, sedangkan anemometer lutron AM-4206 harus diarahkan terlebih dahulu kearah datangnya hembusan angin.

Pada variasi sudut, hal ini untuk melihat respon alat ukur kelajuan dan arah angin dalam menunjukkan arah angin saat di beri angin dengan sudut-sudut berbeda. Jarak kipas angin ke alat memakai jarak yang tetap yaitu pada jarak 0,2 $\mathrm{m}$. Hasil penelitian dengan variasi sudut dapat dilihat pada Tabel 2.

Tabel 2 Hasil pengujian rancang alat secara keseluruhan skala laboratorium terhadap variasi sudut

\begin{tabular}{ccc}
\hline \multirow{2}{*}{ No } & \multirow{2}{*}{ Posisi Sudut } & Alat Ukur Kelajuan dan Arah Angin \\
\cline { 3 - 3 } & $0^{\circ}$ & Arah Angin \\
\hline 1. & $45^{\circ}$ & Utara \\
2. & $90^{\circ}$ & Timur Laut \\
3. & $135^{\circ}$ & Timur \\
4. & $180^{\circ}$ & Tenggara \\
5. & $225^{\circ}$ & Selatan \\
6. & $270^{\circ}$ & Barat Daya \\
7. & $315^{\circ}$ & Barat \\
8. & & Barat Laut \\
\hline
\end{tabular}

Pada variasi sudut ini alat ukur kelajuan dan arah angin berhasil merespon dengan tepat dari mana asal angin berhembus. Arah angin yang deteksi ada delapan arah mata angin. Hasil arah angin lalu ditampilkan pada layar LCD.

\subsubsection{Pengujian Rancang Alat Secara Keseluruhan Skala Lapangan}

Pengujian alat ukur secara keseluruhan skala laboratorium ini dilakukan di BMKG (Badan Meteorologi, Klimatologi, dan Geofisika) Stasiun Meteorologi Kelas II BIM Padang Pariaman. Pada pengujian ini akan membandingkan alat ukur kelajuan dan arah angin dengan anemometer mangkuk milik BMKG untuk melihat keakuratan data. Sumber angin yang digunakan berasal dari alam.

Pengambilan data dilakukan secara bersamaan dimana alat ukur diletakkan bersebelahan dengan anemometer mangkuk milik BMKG. Posisi ketinggian alat berbeda, karena alat anemometer mangkuk milik BMKG diletakkan pada ketinggian $10 \mathrm{~m}$ diatas permukaan tanah. Posisi alat ukur juga harus disesuaikan terlebih dahulu dengan arah mata angin pada kompas. Data akan dikirim ke ruangan kendali yang berjarak $20 \mathrm{~m}$ dari lokasi peletakan alat. 
Tabel 3 Hasil pengujian rancang alat secara keseluruhan skala lapangan

\begin{tabular}{|c|c|c|c|c|c|}
\hline \multirow{2}{*}{ No } & \multicolumn{2}{|c|}{ Anemometer Mangkuk BMKG } & \multicolumn{2}{|c|}{ Alat Ukur Kelajuan dan Arah Angin } & \multirow{2}{*}{$\begin{array}{c}\text { Persentase } \\
\text { Kesalahan } \\
\text { e (\%) }\end{array}$} \\
\hline & Kelajuan $(\mathbf{m} / \mathbf{s})$ & Arah Angin & Kelajuan $(\mathbf{m} / \mathbf{s})$ & Arah Angin & \\
\hline 1. & 2,67 & Barat Daya & 2,22 & Barat Daya & 16,85 \\
\hline 2. & 3,50 & Barat Daya & 3,36 & Barat Daya & 4,00 \\
\hline 3. & 3,00 & Barat Daya & 2,64 & Barat Daya & 12,00 \\
\hline 4. & 2,26 & Barat Daya & 2,22 & Barat Daya & 1,77 \\
\hline 5. & 1,85 & Barat Daya & 1,86 & Barat Daya & 0,54 \\
\hline 6. & 3,00 & Barat Daya & 3,00 & Barat Daya & 0,00 \\
\hline 7. & 4,32 & Barat Daya & 4,50 & Barat Daya & 4,16 \\
\hline 8. & 3.29 & Barat Daya & 2,64 & Barat Daya & 19,75 \\
\hline 9. & 3,90 & Barat Daya & 4,50 & Barat Daya & 15,38 \\
\hline 10. & 3,29 & Barat Daya & 3,36 & Barat Daya & 2,12 \\
\hline \multicolumn{5}{|c|}{$\overline{\mathbf{e}}$} & 7,65 \\
\hline
\end{tabular}

Tabel 3 menunjukkan bahwa nilai kelajuan yang terukur pada alat ukur tidak berbeda jauh dengan anemometer mangkuk milik BMKG. Arah angin yang didapatkan sesuai dengan arah angin yang terbaca pada alat anemometer mangkuk milik BMKG yaitu barat daya. Persentase kesalahan rata-rata yang didapatkan pada pengujian nilai kelajuan angin adalah 7,65\%. Nilai ini menandakan adanya perbedaan. Perbedaan terjadi pada posisi peletakan alat yang tidak pada ketinggian yang sama. Peletakan anemometer mangkuk milik BMKG diletakkan pada ketinggian $10 \mathrm{~m}$ diatas permukaan tanah, sedangkan peletakan alat ukur kelajuan dan arah angin diletakkan tepat diatas permukaan tanah. Pada posisi peletakan alat anemometer milik BMKG, alat tidak terhalang apapun sehingga dapat mengukur angin dengan tepat.

\section{KESIMPULAN}

Berdasarkan penelitian ini, maka dapat ditarik beberapa kesimpulan yaitu rancang bangun alat ukur kelajuan dan arah angin telah berhasil dikembangkan dengan menggunakan sistem telemetri nirkabel menggunakan transceiver nRF24L01+. Sistem telemetri nirkabel ini mampu mentransmisikan data kelajuan dan arah angin. Jangkauan jarak maksimum yang didapatkan tanpa penghalang $1000 \mathrm{~m}$, bila terdapat penghalang pada cuaca cerah $650 \mathrm{~m}$, dan terdapat penghalang pada cuaca hujan $485 \mathrm{~m}$. Persentase kesalahan rata-rata alat yang didapatkan sebesar 4,54\% dan 7,65\% jika dibandingkan anemometer lutron AM-4206 dan anemometer mangkuk milik BMKG Stasiun Meteorologi Kelas II BIM Padang Pariaman. Alat ukur arah angin berhasil mendeteksi dan menampilkan arah angin yang sama dengan yang terbaca pada anamometer mangkuk milik BMKG.

\section{DAFTAR PUSTAKA}

Derek, O., 2016, Rancang Bangun Alat Monitoring Kecepatan Angin dengan Koneksi Wireless Menggunakan Arduino UNO, Journal Teknik Elektro dan Komputer, Vol.5, No.4, Jurusan Teknik Universitas Sam Ratulangi

Hudaya, I., 2013, Perancangan Alat Monitoring Kecepatan dan Arah Angin dengan Menggunakan Komunikasi Wireless, Jurnal Saintia Fisika Universitas Sumatera Utara, Vol.2, No.1, Jurusan Fisika Universitas Sumatera Utara

Middleton, K.W.E., 1969, Invention of the Meteorological Instruments, Johns Hopkins Press, Baltimore

Pesma, R.A., 2013, Rancang Bangun Alat Ukur Kelajuan dan Arah Angin Berbasis Mikrokontroler ATmega8535 Menggunakan Sistem Sensor Cahaya, Skripsi, Jurusan Fisika, Universitas Andalas, Padang 